the meeting (three working days) little time was allotted to each paper and three simultaneous sessions had to be organized, with typically six papers in a 75 minute session. Most chairmen used about half the allotted time for short presentations and the remainder for discussion. This made the sessions more coherent, but made it difficult to attend selected papers in different sessions.

However, even though an ideal format for such a meeting was not reached in Bordeaux, a serious attempt was made to eliminate the drudgery of a long incoherent succession of short contributed papers. Equally important, the atmosphere at the meeting was exciting, many new contacts were established and one came away with the feeling that continent-wide collaboration between crystallographers in Europe had received a boost which can only be beneficial.

\section{P. Coppens}

\section{Chemistry Department at Buffalo \\ Buffalo \\ New York 14214 \\ U.S.A.}

State University of New York

(Received 11 October 1973)

\section{Crystallographers}

This section is intended to be a series of short paragraphs dealing with the activities of crystallographers, such as their changes of position, promotions, assumption of significant now duties, honours, etc. Items for inclusion, subject to the approval of the Editorial Board, should be sent to the Executive Secretary o should be sent to the Executive Secretary $O$ the International Union of Crystallography (J.N. 13 White Friars, Chester CH1 $1 \mathrm{NZ}$, England).

Professor Charles A. Coulson died on Monday, January 7 th. His very varied career, which included appointments in mathematics, physics, chemistry and even a year of research in biology, reflected his wide and absorbing interest in the mathematical understanding of the structure of matter and particularly of molecules. His influence on chemical crystallography was intimate and profound. For years, crystallographers have brought results of all accurate structure analyses to Charles Coulson and have taken from his a new understanding of their observations and new ideas for research. He was a remarkably lucid lecturer, who spoke all over the world on scientific problems, and on science and religion. Yet he seemed to be always at home in Oxford for those who needed him. He held the Rouse Ball chair of applied mathematics at Oxford from 1952 to 1972 and then, in the last years of his life, became in name what he had long been in fact, the University's first Professor of Theoretical Chemistry.

Professor E. C. Lingafelter succeeds R. A. Young as President of the American Crystallographic Association for 1974. Dr M. H. Mueller will continue to serve as Secretary of A.C.A. until the end of 1975. Dr R. D. Burbank and Dr C. N. Caughlan have been elected Vice-President and Treasurer, respectively, for 1974.

Professor A. C. T. North has been appointed to the Chair of Biophysics and Head of the Astbury Department of Biophysics at the University of Leeds. Previously he was a Senior Research Officer in the Laboratory of Molecular Biophysics at the University of Oxford.

\section{International Union of] Crystallography] \\ Commission on Crystallographic Computing}

Call for Material for Supplement to the Third Edition of the

World List of Crystallographic Computer Programs

The third edition of the World List of Crystallographic Computer Programs has been published in the Journal of Applied Crystallography (1973), 6 (4), pp. 309-346. The required information for submission of programs to this list was first described in an announcement [Acta Cryst. (1971), A 27 (4), 393-396]. and again as part of the World List.

Since a large number of useful crystallographic computer programs were not included in the third edition, the Commission on Crystallographic Computing has decided to publish supplements to the list on an annual basis, until such time as a completely new list is required. This work is done for the benefit of crystallographers in general, and to avoid any wasteful duplication of effort. Therefore, the Commission wishes to take this opportunity to urge all crystallographer programmers to take the time to prepare the material required for for the proposed supplement. The for- mats and abbreviations will be identical with those for the third edition. Please send the necessary information about your unlisted programs, within two months from the date of publication of this announcement, to the Editor in charge of the Supplement: Dr G. C. Bassi, CNRS Laboratoire de Rayons $X$, B.P. No. 166, Centre de Tri, 38042 Grenoble Cedex, France.

\section{Notes and News}

Announcements and other items of crystallographic interest will be published under this headgraphic interest will be published under this heading at the discretion of the Editorial Board. The
notes (in duplicate) should be sent to the Execnotes (in duplicate) should be sent to the Exec-
utive Secretary of the International Union of utive Secretary of the International Union of
Crystallography (J. N. King. International Union of Crystallography, 13 White Friars, Chester CH1 $1 \mathrm{NZ}$, England).

The Montpellier Documentation Centre has just issued a new index of French industrial and university laboratories which produce mineral crystals. This index supersedes the index prepared in 1967.

This index may be obtained by sending the sum of three francs (postagestamps) or four international reply coupons to Professor Vergnoux, Centre de Documentation sur les Synthèses Cristallines, Université des Sciences et Techniques du Languedoc, Place Eugène Bataillon, F-34060 Montpellier Cedex, France.

\section{Book Reviews}

Works intended for notice in this column should be sent direct to the Book-Review Editor $(M$. $M$. Woolfson, Physics Department, University of York, Heslington, York YO1 5DD, England). As far as practicable books will be reviewed in a country different from that of publication.

\section{The opaqne minerals in stony meteorites. By PaUL RAmDoHr. Pp. 245, Plates 70. Amsterdam: Elsevier, 1973. Price $f 65$ (about U.S. $\$ 25.20$ ).}

This relatively small book is rather of the nature of a final research report of the author's own extensive work concerning the examination of polished sections of some 350 meteoritic stones. As the title indicates, the interest here is not in the dominant silicate minerals but in the less abundant opaque or semi-opaque minerals and the emphasis is on the 